\title{
Jurnalisme Profesional Pilar Demokrasi?: Analisis Kritis Perspektif Anthony Giddens
}

\author{
Ahmad Alwajih \\ Alumnus Program Studi Ilmu Komunikasi UII; \\ Mahasiswa S2 Ilmu Komunikasi Universitas Gadjah Mada, Yogyakarta
}

\begin{abstract}
Many scholars believe that professional journalism is independence structure, so it plays importance role in democracy process. However, this notion is inadequate. There are critics came from the scholars who thought that journalism is no longer independent. It now depends on larger structures, such as markets and political interests. This article tries to map these two sides through the Anthony Giddens's theoretical perspective, which puts journalism as a social agent and always confronts with other larger structures.
\end{abstract}

Keywords: Professional journalism, democracy, critics of professional journalism, social agent, structures

\begin{abstract}
Abstrak
Banyak akademisi percaya bahwa jurnalisme profesional adalah struktur yang independen, karenanya memiliki peran penting dalam proses domkrasi. Akan tetapi, pernyataan ini tak lagi mumpuni. Banyak kritik datang dari sejumlah akademisi lain yang menganggap bahwa jurnalisme sudah tidak independen lagi. Jurnalisme kini dipengaruhi oleh struktur yang lebih besar, seperti pasar dan kepentingan politik. Artikel ini mencoba untuk memetakan dua sisi ini melalui perspektif teoretis Anthony Giddens. Perspektif ini meletakkan jurnalisme sebagai agen sosial yang selalu bertentangan dengan struktur kekuasaan.
\end{abstract}

Kata Kunci: Jurnalisme profesional, demokrasi, kritik atas jurnalisme profesional, agen sosial, struktur

\section{Pendahuluan}

Perdebatan sengit dalam teori jurnalisme tidak hanya terjadi antara disiplin jurnalisme melawan disiplin keilmuan lain, seperti ditunjukkan oleh Keith Windschuttle di kubu jurnalisme dan Julia Ravell yang mewakili cultural studies (Windschuttle, 1998; Ravell, 1998). Perdebatan itu juga terjadi di tubuh jurnalisme sendiri, baik itu berada pada tataran konsep filosofis, maupun di level praktis. Oleh karenanya, penulis akan membatasi permasalahan karena luasnya jangkauan perdebatan di level teoretik jurnalisme.

Artikel bercorak literature review ini mencoba memetakan perbenturan dua kubu di tubuh jurnalisme sendiri, berkaitan dengan independensi jurnalisme dalam mengawal proses demokrasi. Dua kubu yang saling mempertahankan idealismenya itu 
adalah: Pertama, pemikiran yang masih optimis bahwa jurnalisme profesional mampu menjalankan perannya sebagai pengawal proses demokrasi independen. Kedua, pemikiran yang skeptis (jika tidak mau dikatakan pesimis) karena jurnalisme yang ada sudah dianggap tidak sanggup lagi untuk menjalankan peran sentralnya.

Sebagai pijakan teoritis, penulis akan meminjam cara pandang Anthony Giddens yang menitikberatkan pada tarikulur antara agen dan struktur. Dengan demikian, koridor perdebatan ini akan meletakkan posisi jurnalisme sebagai agen sosial yang berkelindan dengan agen lain, sekaligus struktur dominan lainnya (ekonomi dan politik).

Pembahasan akan dimulai dengan menjabarkan konsep kunci Anthony Giddens yang menjadi pengantar analisis artikel ini. Kemudian, penulis mencoba menghubungkan jurnalisme dan demokrasi dengan melacak basis ideologinya. Setelah itu, mengidentifikasikan argumentasi masingmasing kubu. Di akhir tulisan, penulis mencoba menyajikan resolusi atas perdebatan tersebut dengan argumen teoritis yang juga bersumber dari literatur ilmiah.

\section{Basis Teori Anthony Giddens}

Dunia kini sedang lari tunggang langgang (runaway world), demikian bunyi salah satu pijar pemikiran Anthony Giddens (Juliawan dalam Majalah Basis,
2000: 49). Memasuki era modern, setiap fenomena seringkali bermata ganda (double-edged phenomenon). Tidak berlebihan kiranya, sebab institusiinstitusi moderen menyediakan wilayah keamanan dan kenyamanan yang makin menanjak kualitasnya. Namun, di sisi lain masih terdapat risiko-risiko yang mengintai dari sebuah sudut gelap. Tentunya ini menggelisahkan. Ia menyebutnya dengan istilah juggernaut, yaitu dualitas antara keuntungan-risiko usaha mengendalikannya kadang-kadang menentramkan dan terasa jinak, tetapi usaha yang sama akan tampak mencekam karena jalan yang dilewatinya sarat bahaya.

Berangkat dari kondisi dunia yang demikian, maka pendekatan klasik dalam dunia sosial rasanya tak cukup kompatibel untuk membacanya. Fenomena ini bukanlah sekadar peran sosial seperti dalam fungsionalisme struktural (Talcott Parsons), bukan kode-kode tersembunyi (Levi Strauss), bukan juga keunikansituasional seperti dalam teori interaksionisme (Erving Goffman). Bagi Giddens, fenomena sosial haruslah dilihat bukan secara keseluruhan, bukan bagian, bukan struktur, dan bukan pelakuperorangan, melainkan titik temu keduanya, yaitu "praktik sosial yang berulang serta terpola dalam lintas ruang dan waktu”. Giddens akhirnya menawarkan teori strukturasi (structuration theory) sebagai kritik atas teori-teori pendahulunya dan cara 
pandang yang dianggapnya mampu meneropong era juggernaut ini (Priyono, 2008: 16-17).

Teori strukturasi mengandaikan hubungan antara pelaku dan struktur berupa relasi dualitas, bukan dualisme (berdiri sendiri-sendiri). Dualitas terletak dalam fakta, bahwa skema mirip aturan yang menjadi prinsip bagi praktik di berbagai tempat dan waktu - ialah hasil dari keterulangan tindakan, sekaligus medium bagi berlangsungnya praktik sosial. Skema ini disebut struktur. Berbeda dengan teori lain yang menyatakan struktur selalu mengekang, struktur dalam teori Giddens juga bersifat memberdayakan

(enabling), memungkinkan praktik sosial (Priyono, 2008: 19).

Melalui teorinya, Giddens melihat adanya tiga prinsip utama struktur (Priyono, 2008: 20). Pertama, struktur signifikasi (signification) menyangkut skemata simbolik, penyebutan, dan wacana. Kedua, struktur dominasi (domination) yang mencakup penguasaan atas orang (politik) dan barang/hal (ekonomi). Ketiga, struktur legitimasi (legitimation) menyangkut skemata peraturan normatif yang terungkap dalam tata hukum.

Di sinilah Giddens sebenarnya berusaha menunjukkan bahwa struktur hanya bisa dilihat dari totalitas praktik sosial. Reproduksi sosial berlangsung lewat dualitas struktur dan praktik sosial tersebut. Persoalannya, apakah para pelaku tahu akan hal ini, ataukah mirip seperti wayang yang bergerak berdasarkan tangan dalang. Barangkali pelaku tahu, tetapi tidak sadar karena tahu tidak harus diartikan sebagai sadar, apalagi sebagai kapasitas penjelasan eksplisit atas semua proses. Giddens membedakan tipologi kesadaran ke dalam tiga dimensi internal pelaku: motivasi tidak sadar (unconsciousness mitovation), kesadaran praktis (practical consciousness), dan kesadaran diskursif (discursive consciousness). Kunci untuk memahami strukturasi ialah mencermati dengan jeli kesadaran praktis. Reproduksi sosial berlangsung lewat keterulangan praktik sosial yang jarang dipertanyakan lagi atau taken for granted (Priyono, 2008: 21).

Relasi antara struktur, praktik sosial/pelaku, dan sistem sosial dijelaskan oleh Giddens sebagai institusionalisasi dan regularisasi praktik-praktik sosial. Karena sudah terlembagakan, maka niscaya ada kuasa dan dominasi di dalamnya. Bagi Giddens, kuasa (power) harus dibedakan dengan dominasi (domination). Dominasi mengacu pada skemata asimetri hubungan pada tataran struktur, sedangkan kekuasaan menyangkut kapasitas yang terlibat dalam relasi sosial di ranah praktik sosial/interaksi. Dalam sudut pandangnya, kekuasaan bukanlah gejala yang terkait dengan sistem, melainkan kapasitas inheren pada pelaku (aktor), karenanya senantiasa transformatif. 
Kekuasaan terjadi lewat mobilisasi struktur dominasi. Karena kekuasaan adalah kapasitas yang dimiliki pelaku, maka hampir mustahil terjadi totalitas penguasaan atas orang lain, meski di dalam penjara sekalipun (Priyono, 2008: 22).

Selain itu, Giddens juga tidak ingin menghindari terjadinya konflik. Teori strukturasi memaklumkan adanya konflik dan kontradiksi dalam tatanan sosial. Konflik menurut Giddens adalah "pertikaian antar pelaku atau kelompok dalam praktik sosial yang kongkret", sedangkan kontradiksi berarti "kondisi pertentangan prinsip-prinsip struktural pengorganisasian suatu masyarakat" pada tataran signifikansi, dominasi, dan legitimasi.

Berangkat dari titik pijakan teoritis Anthony Giddens inilah, penulis kemudian melihat relasi jurnalisme dan demokrasi dalam level teoretis. Perspektif Anthony Giddens setidaknya bisa diterapkan melalui beberapa preposisi. Pertama, fokus pada institusi sosial. Kedua, transformasi institusi sosial. Ketiga, cara institusi mengubah pola sosial (Ritzer dan Douglas, 2007: 512).

\section{Jurnalisme, Demokrasi, dan Dunia "Juggernaut"}

Jurnalisme selalu dikaitkan dengan proses demokrasi dan disematkan predikat "Pilar Keempat Demokrasi". Jurnalisme tidak hanya berperan sebatas fungsinya dalam menyebarkan informasi ke khalayak luas. Ia juga mengisi posisi penting sebagai agen sosial, yaitu pengawal jalannya proses demokrasi menuju tatanan masyarakat ideal. Dengan demikian, jurnalisme dituntut untuk memegang teguh ideologinya

Misalnya, peran jurnalisme saat mengawal isu-isu internasional seperti Hari Buruh Sedunia di Malioboro yang direkam oleh situs berita SoloPos FM. Dalam berita itu, segenap elemen mahasiswa dan kelompok buruh berjalan mundur sebagai tuntutan agar pemerintah lebih memperhatikan nasib kaum buruh. SoloPosFM melaporkan peristiwa tersebut dengan judul besar "Buruh Gelar Aksi Jalan Mundur di Malioboro" (Buruh Gelar aksi Jalan Mundur di Malioboro, SoloPosFM.com, edisi 1 Mei 2012)

Mark Deuze (2005: 445-446) memandang ideologi bagi jurnalisme ialah semacam proses intelektual yang berlaku sepanjang masa - meliputi segenap ideide dan pandangan, terutama berkenaan dengan isu-isu sosial-politik. Deuze menyebut dengan istilah lain, "ritual strategis" kaum pencari berita. Demi keberlangsungan proses demokrasi, setidaknya jurnalisme harus memenuhi beberapa prasyarat: Pertama, jurnalisme melayani kepentingan publik, sebagai watchdog atau pengawas jalannya pemerintahan. Kedua, jurnalisme harus objektif, yang berarti imparsial dan tidak memihak kepada siapapun. Ketiga, jurnalisme itu otonom dan tidak terikat 
dengan apapun dalam menjalankan tugasnya. Keempat, jurnalisme itu sensitif terhadap praktik imediasi, aktualitas, dan kecepatan. Kelima, jurnalisme memiliki etika.

Faktanya, jurnalisme tidak sekadar menyajikan informasi dan hiburan belaka. Setidaknya ada tiga fungsi utama jurnalisme dari asumsi di atas: Pertama, fungsi kultural, yaitu tiap berita menghasilkan materi kebudayaan, mengembangkan kebudayaan, dan mempertahankan status quo dalam pengertian kultural. Kedua, jurnalisme memainkan fungsi sosialnya dengan menghubungkan individu ke berbagai kepercayaan, relasi-relasi sosial, sehingga membantu individu sukses bermasyarakat, sekaligus membantu individu dengan menyusun, menghubungkan, dan menerapkan satu peristiwa dengan peristiwa lainnya. Ketiga, fungsi politik, yaitu berkenaan dengan kemampuan jurnalisme memobilisasi opini publik (Burton, 2008: 89).

Demokrasi sendiri meniscayakan adanya keterbukaan dan transparansi dalam kehidupan sosial-politik. Jurnalisme yang ideologis dan dipandang fungsional akhirnya menjelma menjadi "ruang publik" yang menampung aspirasi hajat hidup orang banyak sesuai dengan tujuan demokrasi. Habermas melihat fenomena ini sebagai bentuk rasionalisasi kekuasaan yang mungkin (Hardiman, 2009: 127). Masalah relasi antara kemajuan teknis dan dunia kehidupan sosial menjadi kaitan antara teknologi dan demokrasi. Sejauh teknologi dipahami sebagai kontrol rasional ilmiah atas proses-proses yang diobjektifkan, dan demokrasi sebagai bentuk-bentuk komunikasi umum dan publik yang terjamin secara institusional, yang mengemukakan soal praktis tentang bagaimana manusia bisa dan ingin hidup dalam kondisi-kondisi objektif kekuasaan kontrol mereka yang senantiasa meluas. Maka, jurnalisme memperoleh angin segar berkat konsep Habermas ini.

Problem yang dihadapi oleh jurnalisme terutama saat terbentur dengan kepentingan politik maupun kepentingan ekonominya sendiri, tentu porsinya dalam mengawal jalannya demokrasi akan menyusut. Secara serta merta jurnalisme sulit menemukan basis ideologinya kembali. Jurnalisme sebagai agen sosial tidak bisa berdiri sendiri. Ia selalu berkaitan dengan agen sosial lain dan struktur yang lebih besar daripada dirinya.

Menilik dari perspektif Giddens, demokrasi terbayangkan sebagai sosok “juggernaut” yang bergerak manis, tetapi penuh ancaman. Berbeda dari basis pemikiran Habermas yang melihat demokrasi sebagai sebuah peluang pembebasan tanpa dominasi, Giddens justru melihat adanya risiko-risiko dari kehidupan demokrasi ini. Demokrasi dalam perspektif Giddens, sudah sangat berbeda dari cita-cita ideal. Terlebih laju 
kepentingan pasar semakin tak terkendali. Masih adakah demokrasi yang harus dikawal oleh jurnalisme? Jangan-jangan jurnalisme sendiri terjebak dalam panser raksasa bernama demokrasi itu, sehingga tidak memiliki pilihan lain kecuali ikut arus saja.

Sindhunata menulis, demokrasi dewasa ini sangat kental dengan aroma politik bisnis. Sosial-politik pun tidak bisa diperlakukan dengan cara lama, yakni "pembagian keadilan dan kesamaan atas dasar struktur lama.” Kalaupun bisa, mestilah harus bersaing dengan para politisi atau pelaku bisnis lainnya (Sindhunata dalam Majalah Basis: 2000). Selama pergesekan itu terjadi, jelaslah jurnalisme akan berada dalam kondisi terpontang-panting. Satu hal terpenting, di tengah dunia yang tunggang langgang seperti ini, apa yang bisa dilakukan oleh jurnalisme?

Di sinilah titik awal retakan perdebatan antara mereka yang masih optimis bahwa jurnalisme tetap bisa diharapkan sebagai pilar demokrasi independen, dan mereka yang skeptis bahwa jurnalisme saat ini sudah gagal karena tak mampu merdeka dari jerat struktur besar sehingga muncullah jalan keluar baru, struktur baru, atau "Jalan Ketiga” dalam pemikiran Giddens.

\section{Jurnalisme Sebagai Agen Sosial Independen}

Sekalipun jurnalisme profesional terkadang terjerat oleh struktur politik dan ekonomi, bukan berarti hal ini sudah final. Jurnalisme masih bisa diharapkan mengawal jalannya demokrasi di masa mendatang. Temuan-temuan dan hasil analisis penelitian di bawah ini menunjukkan adanya faktor independensi berikut tantangan yang dihadapi jurnalisme.

Kekhawatiran akan kooptasi dalam bentuk apapun yang dihadapi jurnalisme sebenarnya bisa diatasi, yaitu dengan jalan reformasi. Tidak hanya sistem negara saja yang harus direformasi, tetapi juga dari sisi reformasi diri para pelaku jurnalisme. Reformasi di sini ialah kemampuan untuk bersikap produktif dan adaptif terhadap sistem sosial dewasa ini. Tuntutan ini yang nantinya akan menghasilkan produk jurnalistik pemicu aktivitas politik berkualitas, sehingga mampu mengantarkan kehidupan berbangsa dan bernegara ke arah positif. Jurnalisme pun diharapkan mampu menjadi institusi yang memperkuat demokrasi tanpa dikotori kooptasi (Putra, 2004: 131-132).

Ashadi Siregar (2000: 184) berpendapat, yang terpenting untuk jurnalisme adalah mampu keluar dari jeratan hegemonik penguasa. Belajar dari kekangan semasa Orde Baru, jurnalisme tidak dimaksudkan semata bagi kalangan 
wartawan atau pemilik institusi media, bahkan pemegang kekuasaan. Asal kegiatan jurnalisme diberi kebebasan, maka jalannya penyelenggaraan negara bisa diawasi oleh semua pihak tanpa terkecuali. Landasan ideal Ashadi Siregar (2000) bertumpu pada perspektif Hak Asasi Manusia (human rights). Kebebasan diartikan sebagai bagian dari Hak Asasi Manusia, karenanya aktivitas jurnalisme tidak boleh dikekang dalam bentuk apapun. Moral sosial hak asasi manusia selanjutnya juga harus menjadi acuan bagi para pegiat jurnalisme, sehingga acuan moral profesi jurnalisme adalah bentuk penghargaan atas hak asasi manusia juga.

Kebebasan yang dimaksudkan di atas bukan berarti bebas untuk "hantam dulu tanya belakangan”. Jurnalisme tetap wajib mengindahkan fakta sosial sebagai pedoman. Jakob Oetama (2003) menambahkan, fakta memang penting, tetapi makna jauh lebih penting. Jurnalisme dituntut mampu memahami lebih jauh, semisal, mengapa korupsi, kolusi, dan nepotisme merajalela? Wacana yang serius dan bersunggung-sungguh untuk memahami persoalan yang sedang dihadapi masyarakat hari ini akan diyakini memperkuat wacana demokrasi. Jurnalisme pun tidak sekadar mencerdaskan, tetapi juga mencerahkan.

Barangkali cara berpikir dalam koridor ini akan memaksa untuk jangan mau terburu-buru menjatuhi justifikasi apapun. Jangan sampai tergesa-gesa menyatakan bahwa jurnalisme telah gagal menjawab kebutuhan demokrasi. Sebagaimana evolusi sosial, dimana identitas masyarakat terus "menjadi", jurnalisme pastinya tidaklah menjadi ideologi buta yang ajeg dan seolah baku sepanjang masa. Namun jurnalisme sudah pasti berkembang dinamis mengikuti kondisi yang dihadapinya, belum tamat. Itulah alasannya mengapa selalu muncul inovasi terbaru sampai ke ranah teknis, semisal format pelaporan mendalam (indepth reporting). Semua demi menjawab kebutuhan zaman yang senantiasa berubah.

Salah satu terobosannya ialah memperkenalkan jurnalisme publik atau public journalism (Haas dan Linda, 2006: 238). Jurnalisme publik merupakan eksperimen yang dilakukan oleh beberapa institusi media, dengan niat memupuk komitmen bersama masyarakat agar berpartisipasi secara aktif dalam proses demokrasi. Meski niat ini baik karena mengubah relasi antara media dan audiens dengan menggugah peran aktif dalam merayakan demokrasi, tetapi tak urung menuai banyak kritik tajam. Para pengkritisi menilai, ini cuma akal-akalan media atas nama humanisme demi meraup keuntungan semata. Namun, Tanni Haas dan Linda Steiner (2006: 238), menjawab keraguan mereka dengan menguji argumentasi para kritikus yang kurang memadai. Kekhawatiran akan akumulasi profit ternyata kurang sepenuhnya bisa dibenarkan. 
Sebagaimana yang diyakini oleh salah seorang jurnalis Amerika sekaligus mantan pemangku jabatan Press Secretary Gedung Putih, Bill Moyers, api harapan untuk jurnalisme belum berakhir. Dalam ceramah ilmiahnya "Journalism and Democracy", ia mengatakan:

I don't want to claim too much for our craft, but I don't want to claim too little, either....Victory and defeat are both passing moment. There is no end: there are only means. Journalism is a means, and I know think that the act of keeping the record straight is valuable in itself. Serious, careful, honest journalism is essential, not because it is a guiding light, but because it is a form of honorable behaviour, involving the reporter and the reader (Moyers, 2001).

\section{Keraguan Atas Independensi Jurnalisme}

Garis besar mereka yang berseberangan dengan optimisme di atas menyatakan, jurnalisme bukanlah agama yang tidak bisa dibuktikan kekurangannya. Banyak di antara kalangan akademisi menilai konsep jurnalisme yang sudah mapan sekalipun tidak bisa diharapkan terlalu banyak untuk mengawal jalannya demokrasi. Sebagian kritikus merasa skeptis dengan menciutnya jurnalisme sebagai aktor sosial di hadapan struktur besar, sementara sebagian lain menawarkan bentuk jurnalisme alternatif di luar kemapanan konsep jurnalisme.
Lebih tegas lagi argumentasi adanya dekadensi besar-besaran di dalam praktik jurnalisme. Seperti yang berusaha ditunjukkan Puji Rianto lewat risetnya. Ia curiga bahwa media tak lebih dari sekadar struktur ekonomi yang mendambakan akumulasi profit semata dan mengabaikan fungsi-fungsi sosialnya. Imbasnya, produk jurnalistik pun mengalami pergeseran (atau penurunan tajam?), dari yang semula mendukung terciptanya demokrasi ideal, menjadi pedagang informasi belaka. Buktinya, program-program infotainment dan kriminal yang bertebaran di setiap stasiun televisi, seolah-olah hukumnya wajib karena rating-nya bagus. Suratsurat kabar juga tak mau ketinggalan mengubah penampilannya seatraktif mungkin untuk menggaet pelanggan. Maka relasi antara media dan masyarakat tak ubahnya hubungan antara penjual dan pembeli, bukannya partisipan demokrasi yang aktif membangun cita-cita penyelenggaran negara ideal (Rianto, 2005: 113-130).

Menurut Rianto (2005) konteks jurnalisme saat ini tidak bisa terlepas dari paham neoliberalisme yang telah mengakar kuat dalam tatanan ekonomi global (WTO, IMF, Bank Dunia, dan jejaring global governance). Produk jurnalisme merupakan bagian penting dari output media yang memiliki nilai ekonomi sehingga harus mampu mengeruk keuntungan. Kondisi ini membuat jurnalisme tenggelam dalam apa 
yang disebut market-driven journalism, jurnalisme yang dikendalikan pasar.

Jika sudah demikian, jurnalisme akan kehilangan kepercayaan lagi. Di sinilah mulai muncul istilah jurnalisme alternatif (alternative journalism). Konsep umum mengenai jurnalisme alternatif lahir sebagai jawaban atas kuasa kapitalisme dan imperialisme - dinamika dominasi-konsolidasi yang mengglobal. Jurnalisme alternatif ialah sikap resisten atas itu semua. Namun, bukan sekadar konsep jurnalisme lama dengan wajah baru. Jurnalisme alternatif tidak sekadar bertujuan penguatan dan politik saja (empowerement and politics), tetapi juga sampai menyentuh keseharian dan budaya populer. Ia diproduksi oleh amatir di luar institusi media formal, yang tidak pernah mengenyam pendidikan jurnalistik. Justru itulah yang diharapkan dalam jurnalisme alternatif, produk jurnalistik mereka dalam kapasitas mereka sebagai warga (citizens) - aktivis, anggota komunitas, atau fans (Atton dan James dalam Hirst, 2009).

Konsep ini memang mirip dengan jurnalisme warga (citizen journalism), yang memproduksi berita tentang keseharian dari, oleh, dan untuk warga sendiri. Memang itulah yang dimaksud oleh Chris Atton dan James F. Hamilton saat menggagas jurnalisme alternatif. Terlebih dengan dukungan platform teknologi informasi dan komunikasi yang semakin mendukung orang untuk berbagi dengan sesamanya. Fenomena yang sudah dirasa makin menjamur ini oleh Manual Castell (dalam Allan, 2007: 2) diistilahkan dengan "mass-self communication" atau komunikasi diri-massa.

Keluar sama sekali dari kekangan kapitalisme bukan berarti tidak banyak plus-minusnya. Mochammad Nunung Kurniawan (2007) yang pernah meneliti fenomena jurnalisme warga di Radio Elshinta mengatakan, kelebihan yang dimiliki jurnalisme warga ialah beritaberita kiriman warga secara mengejutkan mampu memberitakan hal-hal di luar jangkauan jurnalisme mainstream, bahkan dengan memakai standar berita profesional. Namun, kelemahannya selain terletak pada sarana, juga unsur validasi. Bagaimanapun belum ada standar yang mengatur kualitas berita jurnalisme warga (Kurniawan, 2007: 71-78).

Di luar standar teknis-etis jurnalisme, temuan Kelly Kaufhold, Sebastian Valenzuela, dan Homero Gil De Zuniga (2010) menunjukkan, warga yang terlibat dalam citizen journalism ternyata memiliki kapasitas pengetahuan politik (policital knowledge) setara dengan warga yang mengonsumsi produk jurnalistik profesional. Ini menandakan bahwa jurnalisme alternatif pun juga memiliki kapasitas yang sama dalam hal mengawal jalannya proses demokrasi dengan membangun basis pengetahuan warga. 


\section{Penutup}

Melalui pembacaan atas fenomena ini melalui kacamata Anthony Giddens, penulis memperoleh beberapa kesimpulan. Pertama, dalam mengawal proses demokrasi, kehadiran jurnalisme menempati posisi sentral. Bagi pihak yang masih optimis terhadap independensi jurnalisme profesional, jurnalisme belum habis. Ia masih akan terus berproses mengikuti perubahan sosial-politik di sekitarnya dengan berbagai terobosanterobosan produk jurnalistik. Jurnalisme harus diberi kebebasan yang sesuai dengan Hak Asasi Manusia, dengan begitu jurnalisme akan mampu memonitor jalannya demokrasi secara luwes. Kebebasan ini tidak semata bebas menampilkan fakta, tetapi jurnalisme yang sarat makna.

Kedua, jurnalisme dipandang cacat oleh sebagian pihak yang mencurigai adanya kooptasi dan dominasi dari pihak tertentu. Namun, di antara mereka menyarankan jurnalisme alternatif sebagai upaya solutif untuk mengawal proses demokrasi yang sehat tanpa tekanan. Problemnya, meski pengetahuan politik warga yang berpartisipasi dalam jurnalisme warga itu sama dengan warga yang mengonsumsi produk jurnalistik profesional, keterbatasan alat dan validitas berita akan terus membayangi upaya ini. Sebab, tak ada standar yang pasti dalam jurnalisme warga.
Ketiga, penulis memberi kesimpulan dengan menukil literatur ilmiah lainnya yang mencoba menengahi perdebatan di antara keduanya. Kiranya pemikiran yang disampaikan oleh Steve Paulussen, Ari Heinonen, David Domingo, dan Thorsten Quandt akan memberikan sedikit pencerahan daripada terjebak dalam perdebatan tak berkesudahan (Paulusen, dkk, 2000: 131-154).

Menurut mereka, sederhana saja, lakukan saja keduanya (jurnalisme profesional dan jurnalisme warga). Dikatakan demikian sembari mereka memperkenalkan konsep "Jalan Ketiga”, yaitu jurnalisme berjaringan (networked journalism). Dalam terminologi jurnalisme berjaringan, produk jurnalistik merupakan gabungan antara yang profesional dan amatir untuk mendapatkan berita menarik. Melalui konsep jejaring, keduanya saling berbagi fakta, pertanyaan, jawaban, ide-ide, dan perspektif. Fokus yang hendak dicapai sesungguhnya adalah proses, bukannya hasil akhir.

Perpektif Anthony Giddens tidak lantas menawarkan solusi apapun dalam persoalan dualitas agen-struktur. Setiap konflik atau kontradiksi yang terjadi pada akhirnya akan menimbulkan adanya struktur baru. Anthony Giddens menyebutnya sebagai "Jalan Ketiga" atau katakanlah, struktur baru di antara pergesekan agen dan struktur lama. 
Jika boleh jujur, Jalan Ketiga alias usaha menciptakan struktur baru ini sekalipun pada level praktis sulit untuk dilalui. Di Eropa saja masih jauh dari kesan partisipasi tenaga amatir terhadap kinerja profesional. Di Indonesia sendiri masih kita temui produk jurnalisme seperti ini, tetapi tetap saja itu tidak bisa disebut jurnalisme warga. Misalnya, acara jurnalisme warga di Metro TV memang melibatkan warga untuk menyumbang berita. Namun, pihak pengelolanya masih dipegang penuh oleh Metro TV sebagai tenaga profesional. Meski apa yang disampaikan Steve Paulusen dan kawankawan itu mengawang-awang, tetapi di level teoretik, setidaknya memberikan inspirasi yang penting untuk dikembangkan lebih lanjut.

\section{Daftar Pustaka}

Allan, Stuart. 2007. "Citizen Journalism and The Rise of 'Mass-Self Communication”, Global Media Journal Issue 1 Vol.1.

Burton, Graeme. 2008. Yang Tersembunyi Di Balik Media. Yogyakarta: Jalasutra.

Deuze, Mark, 2005. What is Journalism?: Professional Identity and Ideology of Journalist Reconsidered. London: Sage Publications.
Haas, Tanni dan Linda Steiner. 2006. "Public Journalism a Reply to Critics", Journalism No. 7, hal.238. London: Sage Publications.

Hardiman, F. Budi. 2009. Demokrasi Deliberatif: Menimbang Negara Hukum dan Ruang Publik dalam Teori Diskursus Jurgen Habermas. Yogyakarta: Kanisius.

Hirst, Martin, 2009. "What is Alternative Journalism”, Global Media Journal, Juli.

Kaufhold, Kelly., Valenzuela, Sebastian., \& Gil De Zuniga, Homero. 2010. "Citizen Journalism and Democracy: How User Generated News Use Relates to Political Knowledge and Participation”, J\&MC Quarterly Vol.87 No. 3/4.

Kurniawan, Moch. Nunung. 2007.

"Jurnalisme Warga di Indonesia, Prospek dan Tantangannya”, Makara Sosial Humaniora Vol.11 No.22, Desember.

Majalah Basis Edisi Khusus Anthony Giddens, Nomor 01-02, Tahun ke49, Januari-Februari 2000.

Moyers, Bill. 2001. Journalism and Democracy: on The Importance of Being a Public Nuisance. Ceramah ilmiah dalam perhelatan National Press Club, 22 Maret 2001. 
Oetama, Jakoeb. 2003. Antara Jurnalisme Fakta dan Jurnalisme Makna, makalah ilmiah dalam pidato penerimaan penganugerahan gelar Doctor Honoris Causa dalam bidang Komunikasi dari Universitas Gajah Mada pada 17 April 2003. Tidak diterbitkan.

Paulusen, Steve, dkk. 2007. "Doing it Together: Citizen Participation in The Proffessional News Making Proccess", Observatorio Journal, Vol.3.

Priyono, Harry B. 2008. Anthony Giddens Suatu Pengantar. Yogyakarta: LKiS.

Putra, I Gusti Ngurah. 2004. "Demokrasi dan Kinerja Pers di Indonesia”, Jurnal Ilmu Komunikasi Universitas Gajah Mada Vol.3 No.2, Juni.
Ravell, Julia. 1998. "Cultural Studies Critics Miss The Point”, Asia Pacific Media Educator Issue 4.

Rianto, Puji. 2005. "Jurnalisme Dalam Tatanan Neoliberal dan Krisis Demokrasi”, Jurnal Ilmu Sosial dan Ilmu Politik Universitas Gajah Mada, Vol. 9, No.1.

Ritzer, George dan Douglas J. Goodman. 2007. Teori Sosiologi Modern. Jakarta: Kencana Penada Media.

Siregar, Ashadi. 2000. "Media, Pers, dan Negara”, Jurnal Ilmu Sosial dan Ilmu Politik Universitas Gajah Mada Vol.4 No.2.

Windschuttle, Keith. 1998. Journalism versus Cultural Studies. Australian Studies in Journalism. ."Buruh Gelar aksi Jalan Mundur di Malioboro", SoloPosFM.com 1 Mei 2012, tanggal akses 19 Juni 2012. 